\title{
Casein kinase 2 is a critical determinant of the balance of Th17 and Treg cell differentiation
}

\author{
Sung Woong Jang, Soo Seok Hwang, Hyeong Su Kim, Keoung Oh Lee, Min Kyung Kim, Wonyong Lee, \\ Kiwan Kim and Gap Ryol Lee
}

Th17 cells promote inflammatory reactions, whereas regulatory T (Treg) cells inhibit them. Thus, the Th17/Treg cell balance is critically important in inflammatory diseases. However, the molecular mechanisms underlying this balance are unclear. Here, we demonstrate that casein kinase 2 (CK2) is a critical determinant of the Th17/Treg cell balance. Both the inhibition of CK2 with a specific pharmacological inhibitor, CX-4945, and its small hairpin RNA (shRNA)-mediated knockdown suppressed Th17 cell differentiation but reciprocally induced Treg cell differentiation in vitro. Moreover, CX-4945 ameliorated the symptoms of experimental autoimmune encephalomyelitis and reduced Th17 cell infiltration into the central nervous system. Mechanistically, CX-4945 inhibited the IL-6/STAT3 and Akt/mTOR signaling pathways. Thus, CK2 has a crucial role in regulating the Th17/Treg balance.

Experimental \& Molecular Medicine (2017) 49, e375; doi:10.1038/emm.2017.132; published online 8 September 2017

\section{INTRODUCTION}

Autoimmune diseases are regulated by the balance between $\mathrm{T}$ helper 17 (Th17) cells, which promote inflammatory reactions by secreting interleukin (IL)-17A, IL-17F, IL-21 and IL-22, ${ }^{1-4}$ and regulatory $\mathrm{T}$ (Treg) cells, which suppress effector $\mathrm{T}$ cells and regulate self-tolerance. ${ }^{5,6}$ Despite their conflicting roles, Th17 and Treg cells share a precursor cell (naive CD4 T cells) and an inducing signal (transforming growth factor $\beta$ (TGF $\beta$ )). Depending on other environmental conditions, such as the presence of specific antigens, $\mathrm{T}$ cell receptor (TCR) binding, and the amount of IL-2, IL-6, IL-21 and IL-23, naive CD4 $\mathrm{T}$ cells differentiate into either Th17 or Treg cells. ${ }^{7-10}$ Therefore, the differentiation of Th17 and Treg cells is controlled reciprocally, and the balance between them has a critical role in autoimmune responses.

IL-6, together with TGF- $\beta$, triggers the differentiation of Th17 cells by inducing retinoid-related orphan receptor (ROR)- $\gamma$ t, the key transcription factor that determines Th17 lineage. ${ }^{11,12}$ STAT3, which is phosphorylated and activated by IL-6, is an important component of IL-6-mediated Th17 cell differentiation. STAT3-deficient T cells fail to produce IL-17 and instead induce Foxp3, even in the presence of IL-6 and TGF- $\beta$. ${ }^{13,14}$ Phosphoinositide 3-kinase (PI3K), Akt and mammalian target of rapamycin (mTOR) complexes are also important regulators of Th17 and Treg cell differentiation. The PI3K-Akt axis works downstream of the TCR and CD28 in
T cells and ultimately activates mTOR complexes (mTORC1 and mTORC2). ${ }^{15}$ mTORC1, which is indirectly activated by Akt phosphorylated on Thr308 upon TCR signaling, translocates ROR $\gamma \mathrm{t}$ to the nucleus in a S6K1/2-dependent manner and induces Th17 differentiation. ${ }^{16}$ Then, mTORC2 phosphorylates Akt on Ser473, which inactivates the FoxO proteins that positively regulate Foxp3 expression. ${ }^{17}$ Thus, mTOR-deficient $\mathrm{T}$ cells differentiate into Foxp3+ cells upon TCR stimulation, even in the absence of exogenous cytokines. ${ }^{18}$

Casein kinase 2 (CK2) is a highly conserved serine-threonine kinase that contains two catalytic $\alpha$-subunits $\left(\alpha, \alpha^{\prime}\right)$ and two regulatory $\beta$-subunits that form a holoenzyme tetramer. ${ }^{19}$ CK2 regulates many targets, such as the NF- $\mathrm{KB}$, Wnt, ${ }^{20}$ JAK/STAT (including STAT3) $)^{21,22}$ and $\mathrm{PI} 3 \mathrm{~K} / \mathrm{Akt} / \mathrm{mTOR}^{23}$ signaling pathways, in different types of cells. A recent study showed that CK2 is important for the Th2-restraining function of Treg cells. ${ }^{24}$ However, the role of CK2 during differentiation of other CD4 $\mathrm{T}$ cell subsets is unclear. As CK2 regulates the JAK/STAT pathway and the PI3K/Akt/mROR pathway, we hypothesized that CK2 may regulate CD4 T cell differentiation and, in particular, the Th17/Treg balance.

Here, we examined the role of CK2 in determining the Th17/Treg balance. We found that the inhibition of CK2 by a specific pharmacological inhibitor, CX-4945, or by shRNAmediated knockdown suppressed Th17 cell differentiation and induced iTreg cell differentiation in vitro. CK2 antagonists 
exerted this effect by inhibiting the IL-6/STAT3 and mTOR signaling pathways. Moreover, treatment with CX-4945 ameliorated symptoms of experimental autoimmune encephalomyelitis (EAE), an animal model of a Th17-mediated disease and reduced Th17 cell infiltration into the central nervous system (CNS), thereby demonstrating that inhibiting CK2 may be a potential potent therapeutic strategy for Th17-mediated diseases.

\section{MATERIALS AND METHODS}

Mice

Female C57BL/6 mice (6-8 weeks old) were purchased from Taconic Biosciences (Daehan Bio Link, EumSeong, ChungBuk, Korea) and maintained under specific pathogen-free conditions during the in vivo experiments. All animal experiments were approved by the Sogang University Institutional Animal Care and Use Committee.

\section{In vitro culture of $\mathrm{CD} 4 \mathrm{~T}$ cells}

Naive CD4+ T cells were enriched from the spleen of C57BL/6 mice using the anti-NK1.1 (\#108712, BioLegend; San Diego, CA, USA), anti-CD25 (\#102014, BioLegend), anti-I-A/I-E (\#107610, BioLegend), anti-CD8 $\alpha$ (\#100716, BioLegend), BioMag goat anti-rat IgG (Qiagen; Venio, Netherlands) and BioMag goat anti-mouse IgG (Qiagen) antibodies. Then, the cells were sorted using the biotinylated antiCD62L antibody (\#104404, BioLegend) and anti-biotin microbeads (Miltenyi Biotec; Bergisch-Gladbach, Germany). The cells were then activated by incubation with the plate-bound anti-CD3 $\varepsilon\left(10 \mu \mathrm{g} \mathrm{ml}^{-1}\right.$; $2 \mathrm{C11})$ and anti-CD28 $\left(10 \mu \mathrm{g} \mathrm{ml}^{-1}\right.$; 37.51) antibodies in RPMI-1640 medium supplemented with 5\% fetal bovine serum, 2-mercaptoethanol, MEM amino acids, non-essential MEM amino acids and penicillinstreptomycin (all from Gibco Life Technologies, Carlsbad, CA, USA). Differentiation of Th1 and Th2 cells was induced as previously described. ${ }^{25}$ Mouse recombinant IL-6 $\left(50 \mathrm{ng} \mathrm{ml}^{-1}\right.$; eBioscience; Santa Clara, CA, USA), human recombinant TGF- $\beta 1\left(2 \mathrm{ng} \mathrm{ml}^{-1}\right.$; eBioscience), mouse recombinant IL-1 $\beta$ ( $2 \mathrm{ng} \mathrm{ml}^{-1}$; eBioscience), mouse recombinant TNFa $\left(1 \mathrm{ng} \mathrm{ml}^{-1}\right.$; eBioscience), anti-IFN $\gamma \mathrm{Ab}$ (XMG1.2; $10 \mu \mathrm{g} \mathrm{ml}^{-1}$ ) and anti-IL4 Ab (11B11; $5 \mu \mathrm{g} \mathrm{ml}^{-1}$ ) were added to the culture medium to induce Th17 cell differentiation. Mouse recombinant IL-2 $\left(1 \mathrm{ng} \mathrm{ml}^{-1}\right)$, human recombinant TGF- $\beta 1$ $\left(5 \mathrm{ng} \mathrm{ml}^{-1}\right)$, XMG1.2 $\mathrm{Ab}\left(5 \mu \mathrm{g} \mathrm{ml}^{-1}\right)$ and 11B11 $\mathrm{Ab}\left(5 \mu \mathrm{g} \mathrm{ml}^{-1}\right)$ were added to the medium to induce Treg cell differentiation. CX-4945 (Selleckchem; Houston, TX, USA) was added to the culture medium throughout the study at the indicated concentrations.

\section{Immunoblot analysis}

Immunoblot analysis was performed as previously described ${ }^{25}$ using primary antibodies targeting CK2 $\alpha$ (sc-12738; Santa Cruz Biotechnology; Dallas, TX, USA), $\beta$-actin (sc-47778; Santa Cruz), STAT3 (sc-8019; Santa Cruz), pSTAT3 (sc-8059; Santa Cruz), Akt (\#9272; Cell Signaling Technology; Danvers, MA, USA), pAkt S473 (\#9271; Cell Signaling Technology), pAkt T308 (\#9275; Cell Signaling Technology), pS6 (\#4856; Cell Signaling Technology), ROR- $\gamma$ (B2D; eBioscience) and Lamin B1 (ab16048; Abcam; Cambridge, MA, USA).

\section{CK2 kinase assay}

The kinase activity of CK2 in the cells was determined using a Casein Kinase 2 Assay Kit (\#17-132, Millipore, Bedford, MA, USA) according to the manufacturer's instructions.
Intracellular staining of cytokines and transcription factors For cytokine staining, the cells were re-stimulated with $1 \mu \mathrm{M}$ ionomycin and $10 \mathrm{~nm}$ PMA (both from Sigma-Aldrich, St Louis, MO, USA) in the presence of Brefeldin A (BioLegend) for $4 \mathrm{~h}$ and then stained with an Intracellular Fixation \& Permeabilization Buffer Set (eBioscience). Intracellular Foxp3 staining was performed using a Foxp3 Fix/Perm Buffer Set (BioLegend). To detect the STAT3 phosphorylation, the cells were re-stimulated with IL-6 $\left(100 \mathrm{ng} \mathrm{ml}^{-1}\right.$; eBioscience), fixed and permeabilized with IC Fixation buffer (eBioscience) before staining. Flow cytometric analyses were performed using a FACSCalibur flow cytometer (BD Biosciences; Franklin Lakes, NJ, USA).

\section{RNA isolation and quantitative RT-PCR}

The total RNA was isolated from cells using TRI Reagent (Molecular Research Center; Cincinnati, OH, USA) according to the manufacturer's protocol. Reverse transcription was performed using TOPscript Reverse Transcriptase (Enzynomics; Daejeon, Korea). Quantitative real-time PCR was then performed using HiFast Probe Lo-ROX, HiFast SYBR Lo-ROX master mix (PCR Biosystems; London, UK) and a Roche LightCycler 96 (Roche, Basel, Switzerland).

\section{Cell viability assay}

Cell viability was measured using an EZ-Cytox Cell viability assay kit (DaeilLab Service; Seoul, Korea) according to the manufacturer's protocol. Cultured cells were collected and seeded into a 96-well microplate containing assay reagent. After a $3 \mathrm{~h}$ incubation at $37^{\circ} \mathrm{C}$, the absorbance was measured at $450 \mathrm{~nm}$ using a microplate reader (Bio-Rad; Hercules, CA, USA).

\section{Mouse EAE model}

Female mice (8-10-weeks old) were immunized by a subcutaneous injection with $200 \mu \mathrm{g}$ of myelin oligodendrocyte glycoprotein (MOG) 35-55 (Peptron; Daejeon, Korea) emulsified in complete Freund's adjuvant containing $5 \mathrm{mg} \mathrm{ml}^{-1}$ heat-killed Mycobacterium tuberculosis (Chondrex; Redmond, WA, USA) (day 0). Pertussis toxin (200 ng; List Biological Laboratories; Campbell, CA, USA) was then injected intraperitoneally into the mice on days 0 and 2. Clinical signs were assessed daily and scored as follows: 0 , no symptoms; 1, limp tail; 2 , weakness of hind legs; 3 , complete paralysis of hind legs; 4 , complete hind leg and partial front leg paralysis. The mice were killed on the indicated days, and the brain and spinal cord were isolated and homogenized. Mononuclear cells were isolated by gradient centrifugation with a 30/70\% Percoll gradient (GE Healthcare, Little Chalfont, UK). CX-4945 (Selleckchem) was dissolved in filtered sesame oil. The mice were then administered CX-4945 $\left(50 \mathrm{mg} \mathrm{kg}^{-1}\right.$ per day) or vehicle (same volume) for the indicated times using a gavage needle.

\section{Retroviral transduction of shRNA}

To knockdown Csnk2a, a shRNA vector (based on the retroviral vector MSCV-LMP (GE Healthcare) and harboring a 97mer insert sequence (5'-TGCTGTTGACAGTGAGCGCCCTCACAATGTCATGATAGATTA GTGAAGCCACAGATGTAATCTATCATGACATTGTGAGGTTGCCT ACTGCCTCGGA- $3^{\prime}$ was transfected into Phoenix Eco cells along with a pCL-Eco helper vector. The culture supernatant containing the retrovirus was collected $48 \mathrm{~h}$ post transfection. Activated CD4 T cells were spin-infected (at $200 \times g$ for $90 \mathrm{~min}$ ) with retrovirus-containing culture medium supplemented with $4 \mu \mathrm{g} \mathrm{ml}{ }^{-1}$ polybrene. After 2 days, the cells were analyzed by flow cytometry, and the GFP+ cells were sorted for quantitative RT-PCR (qRT-PCR). 
a

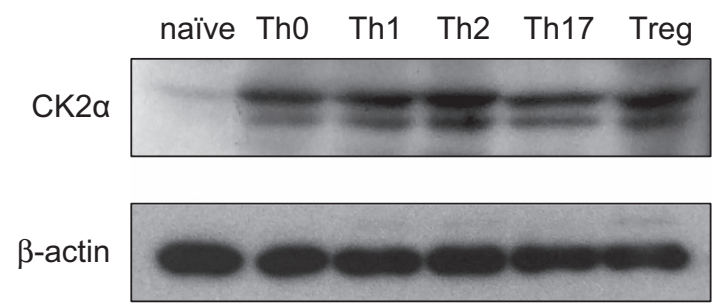

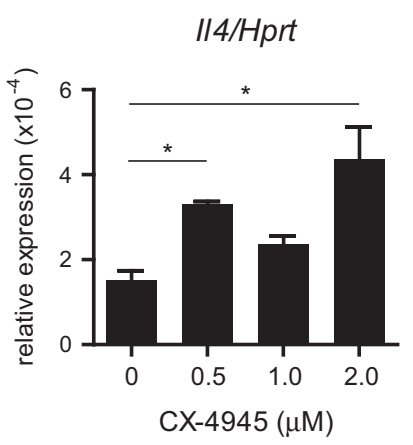

b

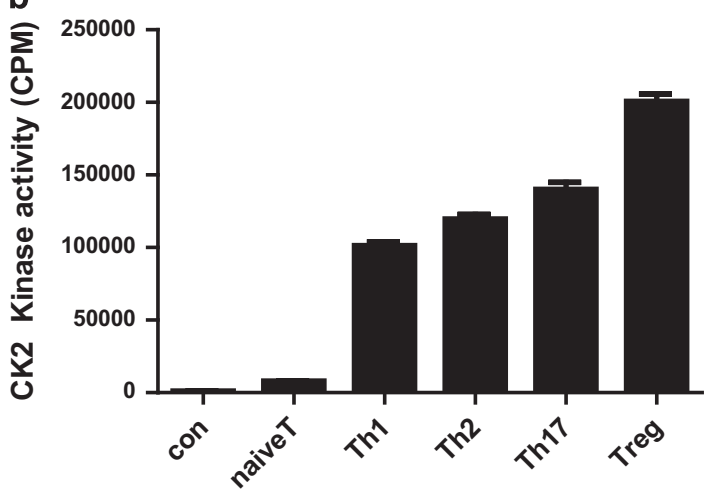

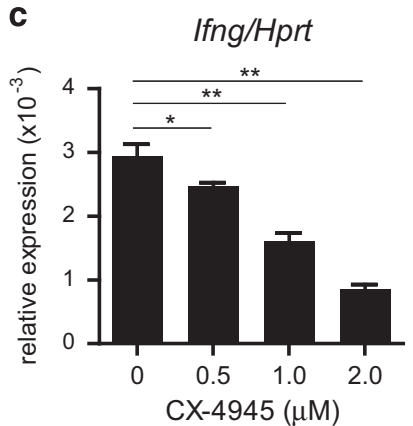

d

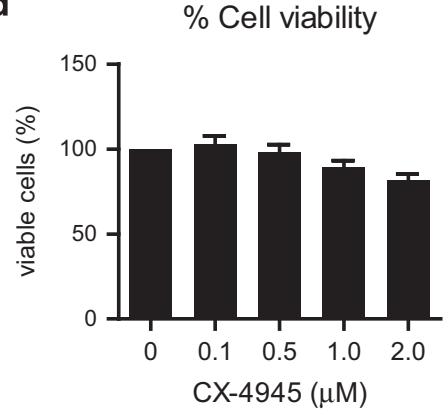

e

Proliferative cells

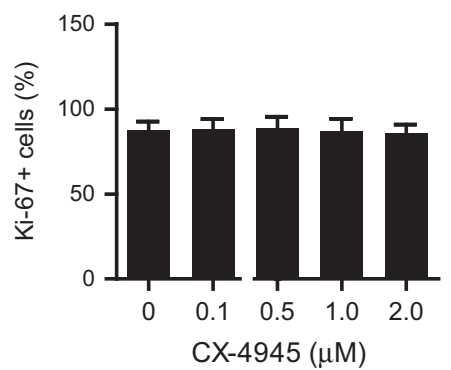

/17/Hprt

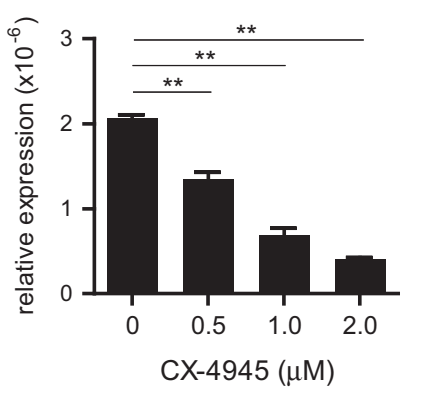

f

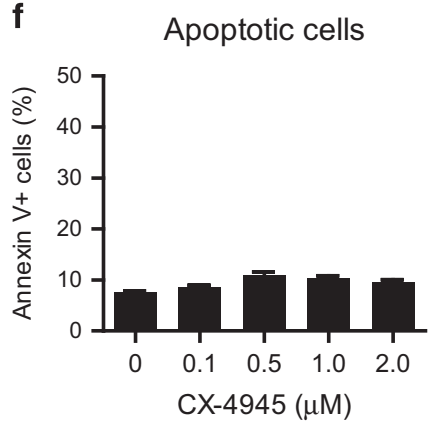

Figure 1 The expression of CK2 and the effect of a CK2 inhibitor, CX-4945, on stimulated CD4 T cells. (a) In vitro-differentiated cells were stimulated under subset-specific polarizing conditions for 3 days. The CK2 $\alpha$ expression levels in whole-cell lysates from naive CD4 $\mathrm{T}$ cells and in vitro-differentiated Th0, Th1, Th2 and iTreg cells were then measured by immunoblot analysis. (b) The CK2 phosphotransferase activities in cell lysates from naive CD4 T cells and CD4 T cell subsets were measured using the Casein Kinase Assay Kit (Millipore). The data are representative of three independent experiments. The control (con) indicates background levels (no cell lysate). (c) Murine naive CD4 T cells were activated by $\alpha \mathrm{CD} 3$ and $\alpha \mathrm{CD} 28$ for $48 \mathrm{~h}$ in the presence of the indicated concentrations of CX-4945, and the relative expression of Ifng, //4, //17a and Foxp3 mRNA was analyzed by quantitative RT-PCR (qRT-PCR). (d) The viability of cells treated as described in c was measured in a MTT assay. (e) The proliferation of cells treated as described in c was assessed by Ki-67 staining. (f) The level of apoptosis of samples treated as described in $\mathbf{c}$ was measured by Annexin $\mathbf{V}$ staining. (e, $\mathbf{f}$ ) The percentages of different CD4 T cell subsets as measured by flow cytometry. The error bars represent the s.d. $P$-values were calculated using Student's t-test. ${ }^{*} P<0.05,{ }^{*} P<0.01$. The experiments were performed three times independently and yielded similar results.

\section{Statistical analysis}

The data are expressed as the mean \pm s.d. Statistical differences between the mean values were determined using Student's $t$-test. Statistical significance was set at $P<0.05$.

\section{RESULTS}

Functional CK2 is expressed by stimulated CD4 T cells To study the role of CK2 in CD4 T cells, we first examined its expression. No expression of $\mathrm{CK} 2 \alpha$, the catalytic subunit of CK2, was detected in naive CD4 $\mathrm{T}$ cells isolated from mouse spleens. However, $\mathrm{CK} 2 \alpha$ was expressed by in vitrodifferentiated CD4 $\mathrm{T}$ cell subsets (Figure 1a). There were no significant differences between the stimulated CD4 $\mathrm{T}$ cell subsets (Th0, Th1, Th2, Th17 and iTreg) in terms of the CK2 $\alpha$ expression levels. To examine whether CK2 is functionally active in CD4 T cells, we then measured the phosphotransferase activity of CK2 in cell lysates prepared from each subset. The kinase activity of CK2 was increased in all effector subsets of CD4 T cells compared with that of naive CD4 T cells (Figure 1b). The CK2 activity was relatively high in 
Th17 cells but was the highest in Treg cells. ${ }^{24}$ Taken together, these results indicate that active CK2 is induced during CD4 $\mathrm{T}$ cell differentiation.

\section{Inhibiting CK2 alters the differentiation status of naive CD4 $\mathrm{T}$ cells}

Next, we studied the effects of CK2 on CD4 T cell differentiation using CX-4945 (Silmitasertib), a potent and selective inhibitor of CK2. ${ }^{26}$ Naive CD4 T cells were stimulated for $48 \mathrm{~h}$ with $\alpha \mathrm{CD} 3$ and $\alpha \mathrm{CD} 28$ in the presence of increasing concentrations of CX-4945. The expression of subset-specific genes was then examined by RT-PCR. Upon activation, naive CD4 T cells expressed various subset-specific genes, including the Ifng, Il4, Ill7 and Foxp3 genes. Surprisingly, CX-4945 led to a marked dose-dependent reduction in the amount Il17 mRNA (Figure 1c). The amount of Ifng mRNA fell, but that of Foxp3 mRNA increased, by CX-4945 treatment (Figure 1c). A cytotoxicity assay revealed that the inhibitor did not affect cell viability when used at a concentration between 0.1 and $2 \mu \mathrm{M}$ (Figure 1d). The proliferation and apoptosis of the CX-4945-treated cells were then examined using Ki-67 and Annexin V staining, respectively. CX-4945 did not affect proliferation or cell death (Figure 1e and f), indicating that CX-4945-induced alterations in CD4 $\mathrm{T}$ cell differentiation status were not due to either phenomenon. Taken together, these results indicate that inhibiting CK2 represses the differentiation of naive CD4 T cells into Th17 cells but induces their differentiation into Treg cells.

CK2 inhibitor alters the balance between Th17 and Treg cells The above results suggest that CK2 reciprocally regulates Th17 and Treg cell differentiation. To examine this in more detail, differentiating Th17 cells were treated with CX-4945 for $72 \mathrm{~h}$, and the subset-specific gene expression was measured. There was a marked reduction in the number of cells expressing IL-17A and IL-17F (Figure 2a and b), whereas the number of cells expressing Foxp3 increased (Figure 2c). Furthermore, CX-4945 increased the Foxp3 expression in iTreg cells (Figure 2d). These changes in protein expression were mirrored by changes in the mRNA expression (Figure 2e and f). To examine alterations in the global gene expression induced by CX-4945 treatment, we performed microarray analysis using the total RNA isolated from Th17 cells treated with $1 \mu \mathrm{M}$ CX-4945 and compared the levels to those from untreated cells (Supplementary Figure S1). We identified 626 genes, mostly encoding phosphoproteins, nuclear proteins and acetylation mediators that were upregulated by CX- 4945 by more than twofolds, and 503 genes that were downregulated by more than twofolds (Supplementary Figure S1a-c). A majority of Th17-related genes was downregulated, whereas a majority of Treg-related genes was upregulated by CX-4945, confirming the qRT-PCR data (Figure 2e and f). The number of Th1 cells was slightly but insignificantly decreased, and Th2 cells were not affected by CX-4945 (Supplementary Figure S2a and b). Taken together, these results suggest that CK2 specifically regulates the reciprocal differentiation of Th17 and Treg cells.
ShRNA-mediated knockdown of CK2 alters Th17 and iTreg differentiation

The role of CK2 in regulating the Th17/Treg balance was further examined using shRNA-mediated knockdown technology. We knocked down the Csnk2a gene, which encodes CK2 $\alpha$, in Th17 and Treg cells using a specific shRNA cloned into a GFP-expressing retroviral vector. The shRNA-transduced (GFP+) cells were sorted, and the relative mRNA expression of Csnk2a, Ill7a, Rorc and Foxp3 was measured by qRT-PCR. One out of the four shRNAs tested reproducibly reduced the expression of Csnk2a mRNA (to $\sim 30 \%$ of that in the controls) and its respective protein (Figure 3a). CK2 $\alpha$ knockdown reduced the Ill7a mRNA expression (Figure 3b) and the percentage of IL-17A-expressing cells (Figure 3c). CK2 $\alpha$ knockdown enhanced Foxp3 mRNA expression (Figure 3b), but it did not alter percentage of Foxp3-expressing cells (Figure 3c). CK2 $\alpha$ knockdown more obviously enhanced both the Foxp3 mRNA expression (Figure $3 \mathrm{~b}$ ) and the percentage of Foxp3-expression cells in iTreg cells (Figure 3c). These results further confirm that CK2 has a critical role in determining the Th17/Treg balance.

\section{CK2 determines the severity of EAE}

Since our data showed that CX-4945 suppresses Th17 cell differentiation in favor of Treg cell differentiation in vitro, we next examined whether it affects Th17-mediated inflammation in a mouse model of EAE. As CX-4945 is an orally bioavailable molecule, ${ }^{26,27}$ it was administered by oral gavage starting on the day of immunization. Surprisingly, the CX-5945-treated group showed much less severe symptoms than the vehicle control group (Figure 4a). Moreover, CX-4945 led to a marked amelioration of the EAE symptoms when given 2 days after symptoms first appeared (Figure 4a). The mice were killed on day 18 and day 21, which correspond to the peak phase and the resolution phase of the disease, respectively. Their spinal cords were harvested and examined by staining with hematoxylin and eosin (H\&E) (Figure 4b) and Luxol fast blue (LFB) (Figure 4c). The spinal cords from control mice showed severe inflammation (Figure 4b) and demyelination (Figure 4c). In contrast, CX-4945treated mice showed less severe inflammation (Figure $4 \mathrm{~b}$ ) and demyelination (Figure 4c). Next, we examined whether cell infiltration into the CNS was affected by CX-4945 in this setting. Mice treated with vehicle or CX-4945 from day 0 were killed at day 18 , and their mononuclear cells were isolated from the CNS to measure the percentages of infiltrating Th1, Th17 and Treg cells. We found a marked reduction in the percentage of Th17 cells after CX-4945 treatment; however, there was little change in Th1 cells, both in the percentage and number (Figure 5a). The percentage of Treg cells was higher in the CX-4945-treated group, but the number was not different (Figure $5 \mathrm{a}$ ). The total number of infiltrated cells in the CX-4945-treated group was much lower than that in the vehicle control group (Figure 5a). Some mice were killed at day 21, and the cell populations were examined again. The percentage and number of CNS-infiltrating Th17 cells were still lower in the group treated with the inhibitor, whereas those for the CNS-infiltrating Treg cells were not affected by CX-4945 treatment (Figure 5b). Taken together, these results 
a
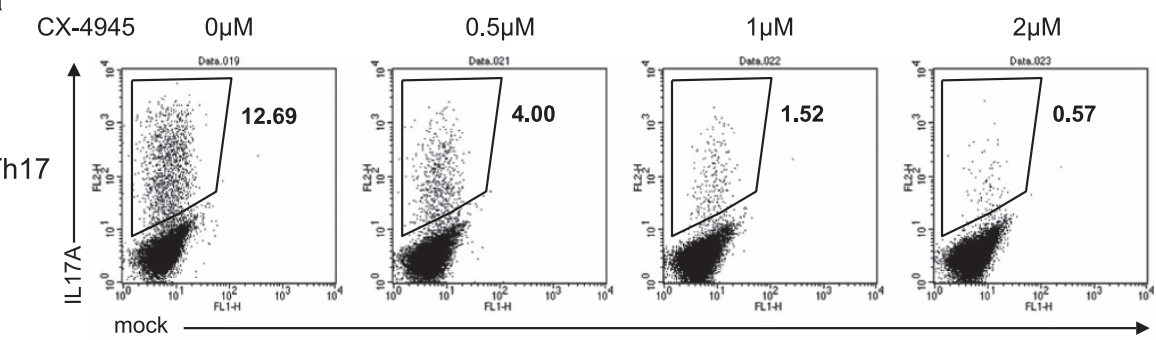

b

CX-4945 $\quad 0 \mu \mathrm{M}$

Th17

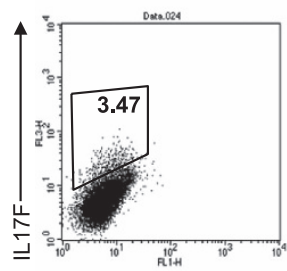

mock

C
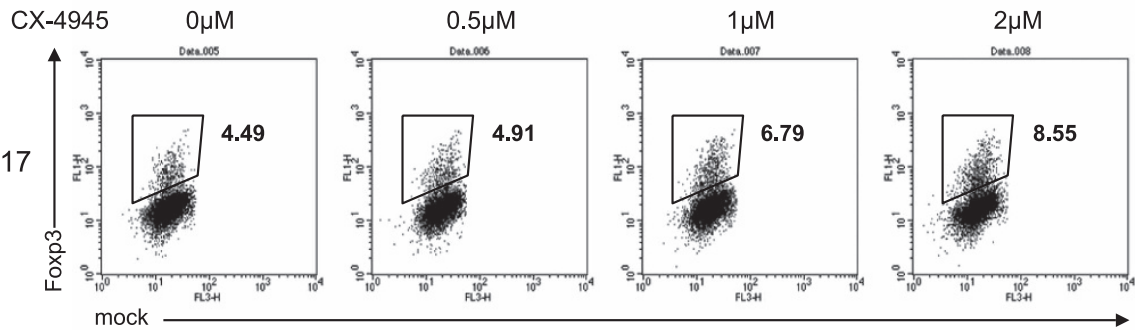

d
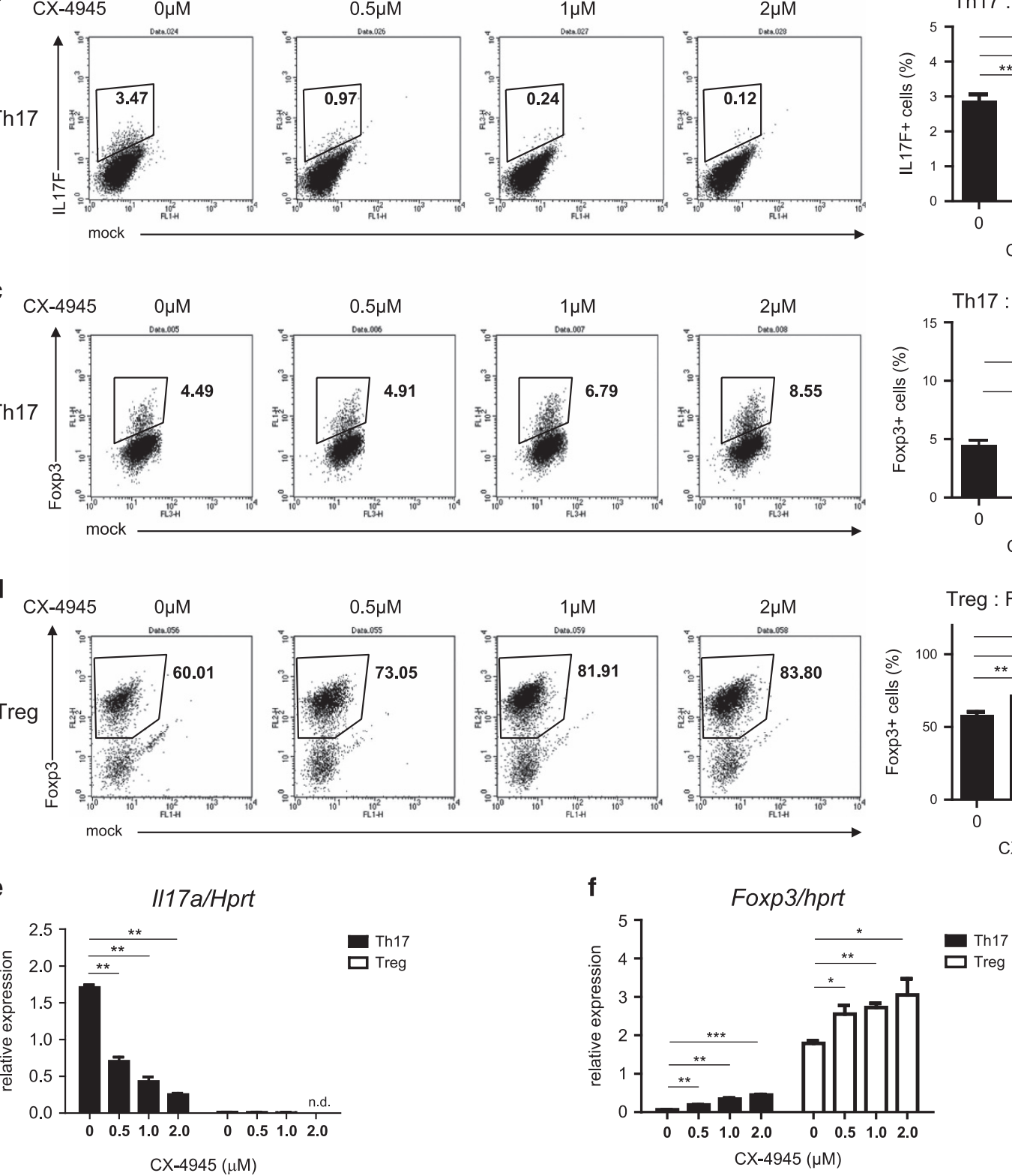

e

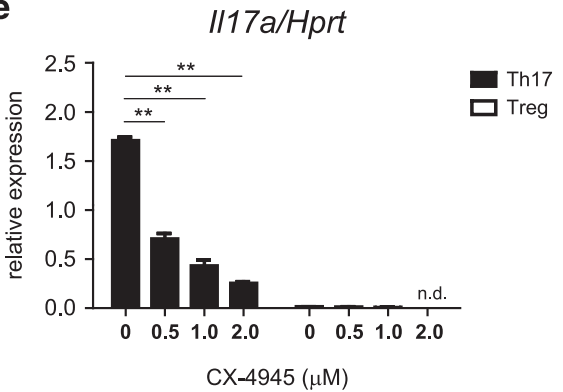

Th17 : IL17A+ cells (\%)

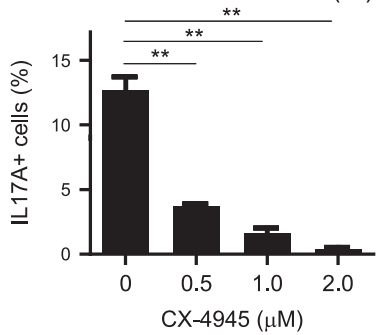

Th17 : IL17F+ cells (\%)

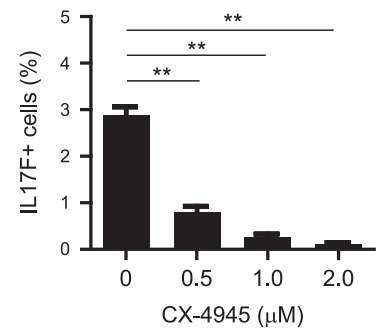

Th17 : Foxp3+ cells (\%)

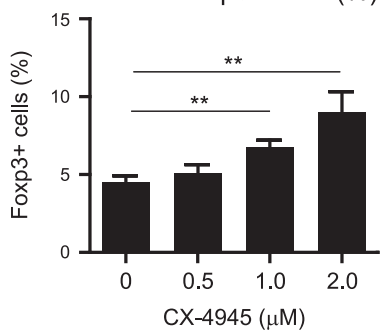

Treg : Foxp3+ cells (\%)

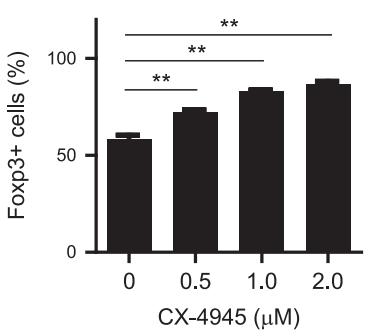

Figure 2 CX-4945 regulates the balance between Th17 and Treg differentiation. (a-c) Naive CD4 T cells were stimulated under Th17-polarizing conditions for 3 days in the presence of the indicated concentrations of CX-4945. The cells were then stained for IL17A, IL-17F and Foxp3, and assessed by flow cytometry (left). The percentages of IL17A+, IL-17F+ and Foxp3+ cells are shown on the right. (d) Naive CD4 T cells were stimulated for 3 days under Treg differentiation conditions in the presence of CX-4945, and the Foxp3 expression was measured by flow cytometry (left). The percentage of Foxp3+ cells is shown (right). (e, f) The relative mRNA expression of II17a and Foxp3 was assessed by quantitative RT-PCR (qRT-PCR). The samples were prepared as described in a-d. The error bars represent the s.d., and $P$-values were analyzed using Student's $t$-test. ${ }^{*} P<0.05,{ }^{* *} P<0.01,{ }^{* *} P<0.001$. The experiments were performed three times independently and yielded similar results. 
show that CX-4945 reduces the severity of EAE symptoms and the infiltration of the CNS by Th17 cells, thereby demonstrating its potent therapeutic effect against EAE and the role of CK2.

\section{CK2 enables STAT3 phosphorylation downstream of IL-6 receptor signaling}

CK2 is necessary for IL-6 receptor signaling, as it increases STAT3 phosphorylation by interacting with JAK kinase. ${ }^{21,22}$
To examine whether CK2 regulates STAT3 activation during Th17 cell differentiation, we treated differentiating Th17 cells with CX-4945 and measured the STAT3 phosphorylation with immunoblotting and flow cytometry analyses. CX-4945 reduced IL-6-dependent STAT3 phosphorylation in a dosedependent manner (Figure 6a and b). To examine whether IL-6 restores Th17 cell differentiation, CX-4945-treated differentiating Th17 cells were treated with excess IL-6 a
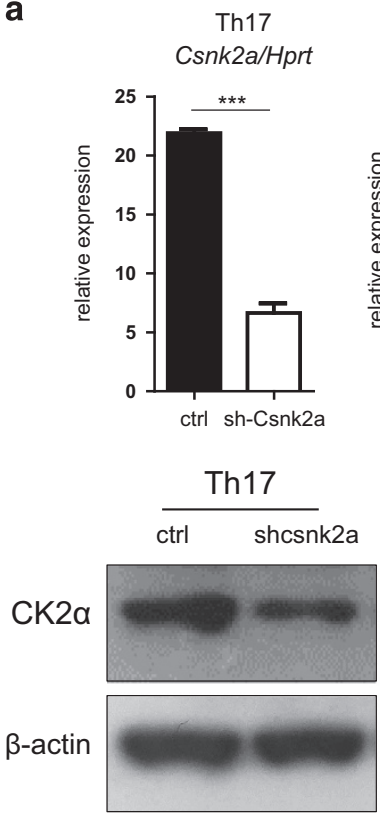

c

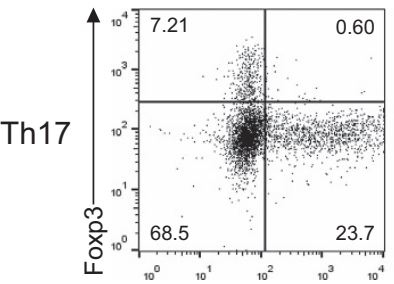

IL17A b
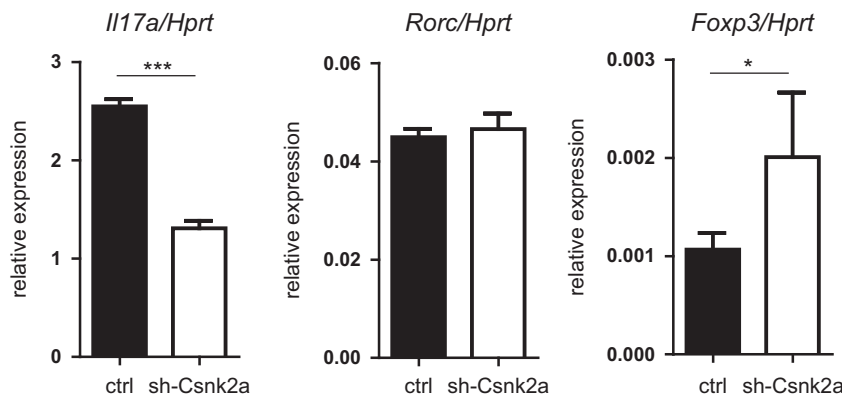

II17a/hprt

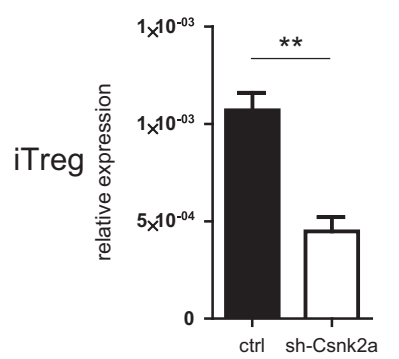

ctrl sh-Csnk2a

IL17A+ cells (\%)
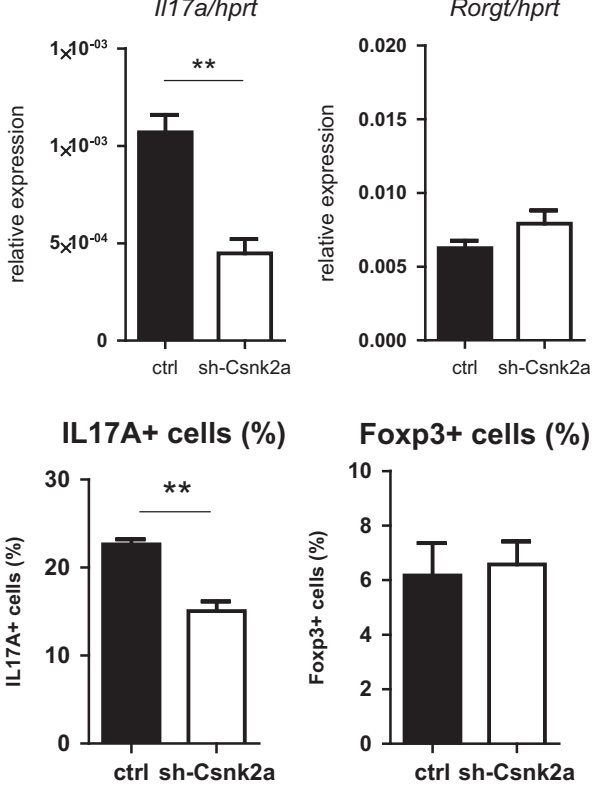

Foxp3/hprt

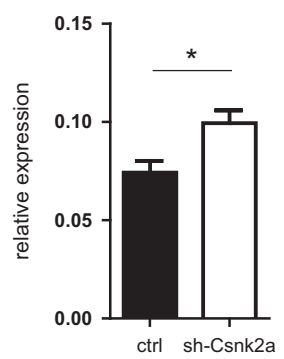

sh-Csnk2a

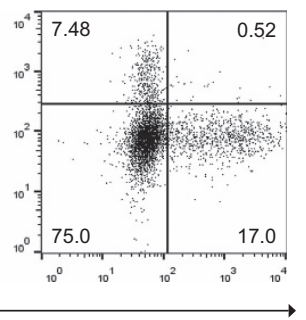

sh-Csnk2a
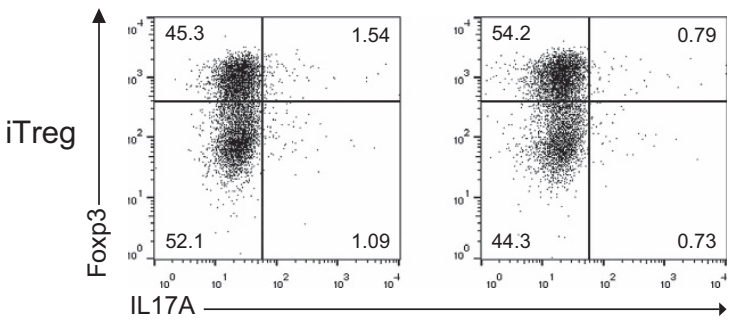

Foxp3+ cells $(\%)$

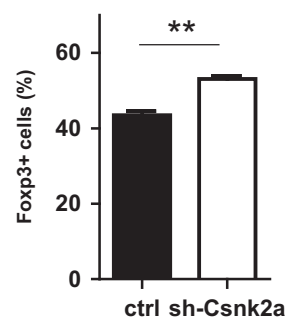

Figure 3 The effect of CK2 knockdown on Th17 and iTreg cells. Naive CD4 T cells were stimulated and transduced with a retroviral vector containing a control vector or sh-Csnk2a. The cells were then stimulated for 3 days under Th17 (a, b) or Treg (c) differentiation conditions and stained for intracellular IL-17A and Foxp3 expression. The cells were gated on GFP expression (b, c). GFP+ cells were sorted, and the relative amounts of Csnk2a, /117a, Rorc and Foxp3 mRNA were measured by quantitative RT-PCR (qRT-PCR) (a). The error bars represent the s.d., and $P$-values were calculated using Student's $t$-test. ${ }^{* *} P<0.01$, ${ }^{* *} P<0.001$. The experiments were performed three times independently and yielded similar results. 
a

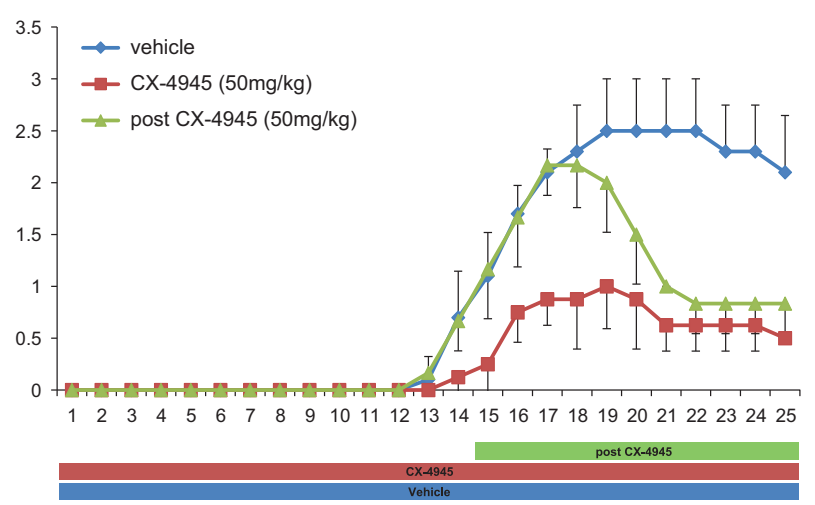

b day 18

day 21

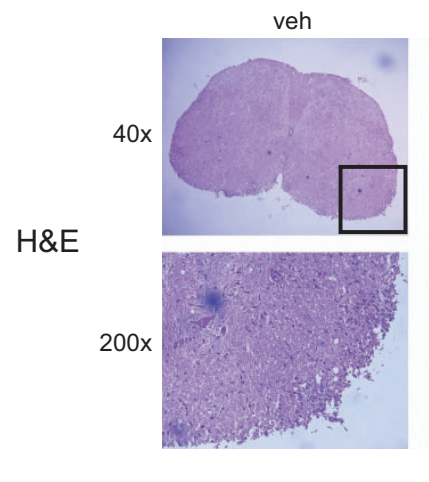

c

day 18
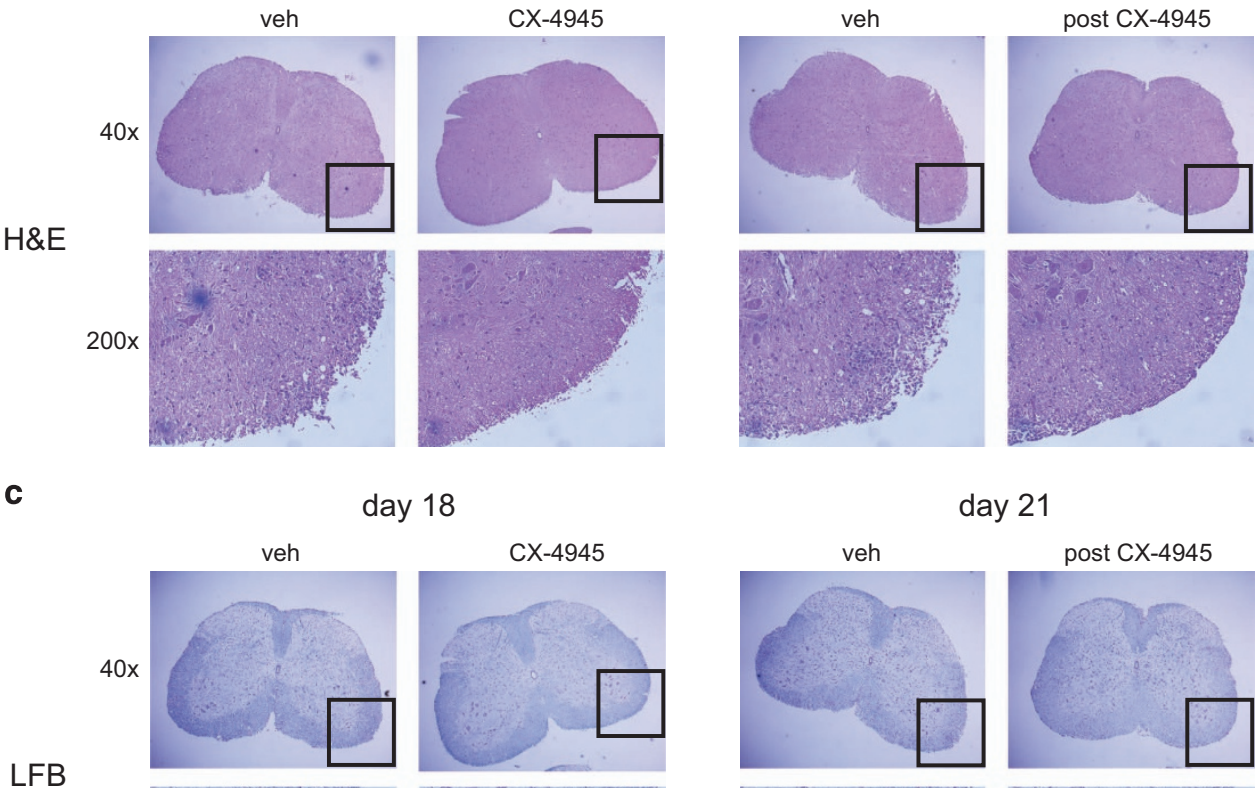

CX-4945
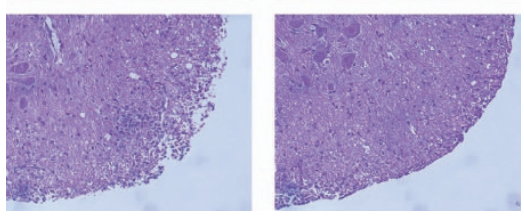

LFB
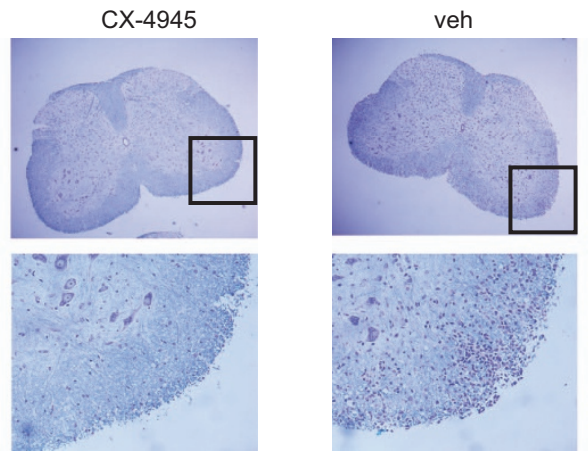

day 21

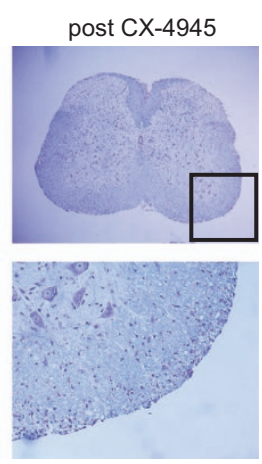

Figure 4 CX-4945 reduces the severity of experimental autoimmune encephalomyelitis (EAE) symptoms. (a) Clinical scores were measured daily after immunization $(n=5)$. Mice received CX-4945 (50 mg kg-1 per day) or vehicle orally via a gavage needle either immediately after immunization or 2 days after the symptoms first appeared. (b, c) EAE-induced mice (a) were killed at day 18 or 21 . (b) Hematoxylin and eosin (H\&E)-stained sections of the spinal cords from EAE-induced mice. Magnified regions are shown as rectangles. (c) Luxol fast blue (LFB) stained sections of the spinal cords from the mice. Magnified regions are shown as rectangles. The experiments were performed three times independently and yielded similar results. The data are representative of three individual mice, all with similar results.

(200 or $500 \mathrm{ng} \mathrm{ml}^{-1}$ ); the results showed that it did not restore the differentiation (Figure $6 \mathrm{c}-\mathrm{f}$ ), indicating that CK2 works downstream of IL-6 receptor signaling. These results suggest that CK2 promotes Th17 differentiation by enabling STAT3 phosphorylation downstream of the IL-6 receptor signal.

\section{CK2 acts via the Akt/mTOR signaling pathway}

TCR and CD28 signaling induces the mTORC2-mediated phosphorylation of Akt at Ser473 and the PDK1-mediated phosphorylation at Thr308. ${ }^{28,29} \mathrm{CK} 2$ activates Akt, ${ }^{30,31}$ and the activation of Akt/mTOR signaling inhibits Treg differentiation and induces effector $\mathrm{T}$ cell differentiation. ${ }^{15}$ Therefore, we tested the possibility that CK2 exerts its effect on Th17 cell differentiation via Akt/mTOR signaling. We found that CX-4945 repressed the phosphorylation of Akt at Ser473, a direct target of mTORC2, upon TCR-re-stimulation (Figure 7a). CX-4945 also repressed the phosphorylation of Akt at Thr308 and S6, both downstream targets of Akt/mTORC1 signaling (Figure 7b). The shRNA-mediated knockdown of CK2 $\alpha$ also reduced the phosphorylation of Akt at Ser473 and Thr308 (Figure 7c), consistent with the CX-4945 experiment. As it has been reported that the 
a

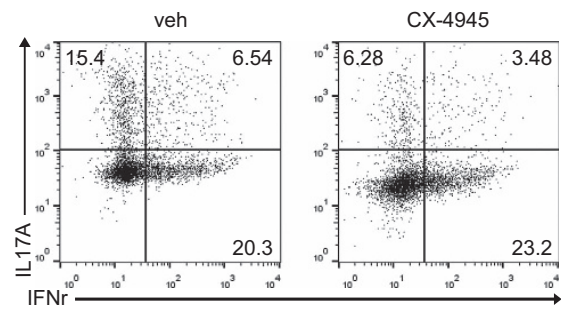

d18

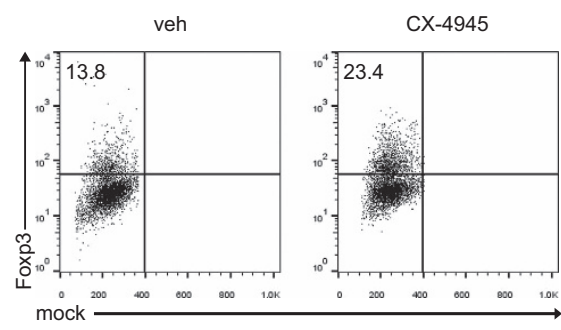

b

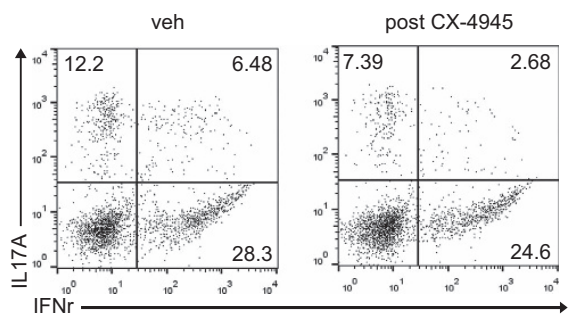

d21

CNS

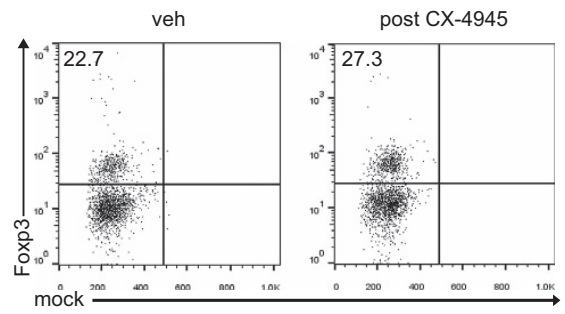

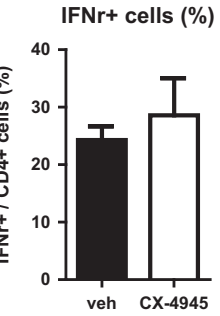

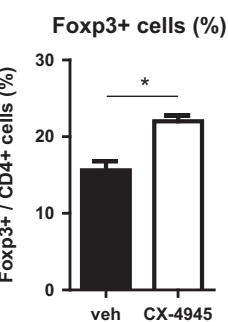

veh CX-4945
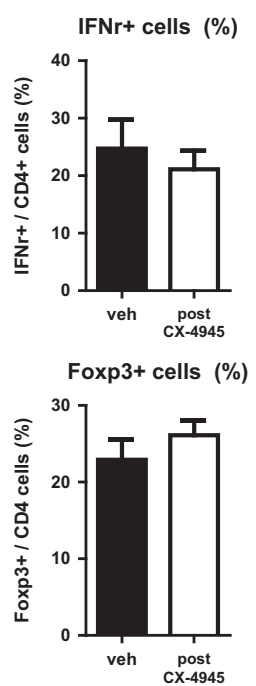
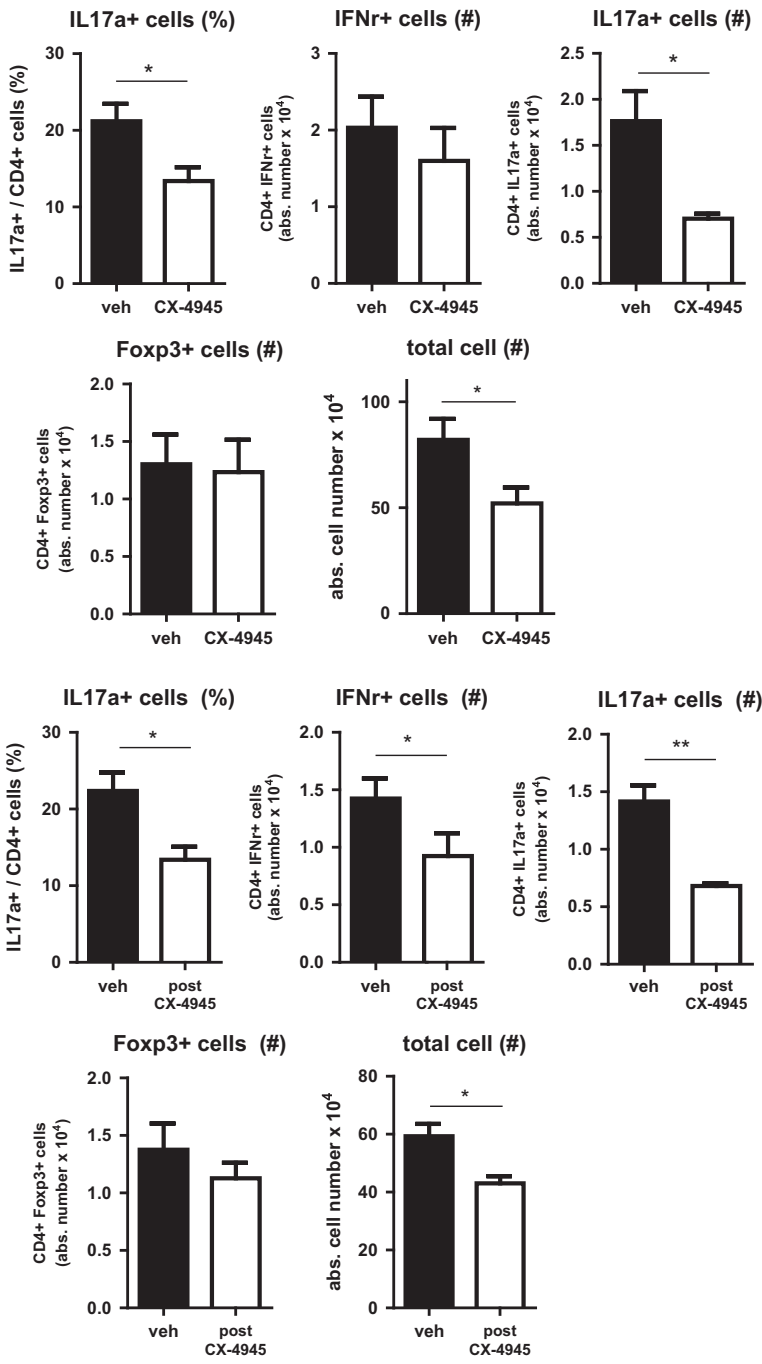

Figure 5 CX-4945 reduces the infiltration of Th17 cells in the central nervous system (CNS). Experimental autoimmune encephalomyelitis (EAE)-induced mice in Figure 4 were killed on day 18 (a) or 21 (b), and the mononuclear cells were isolated from the CNS. The intracellular expression of IL-17A, IFN $\gamma$ and Foxp3 by CD4+ cells was measured by flow cytometry. The experiments were performed three times independently and yielded similar results. The data are representative of three individual mice, all with similar results.

PIK3/Akt/mTOC1 axis controls Th17 differentiation by regulating the nuclear translocation of $\mathrm{ROR} \gamma \mathrm{t},{ }^{16}$ we next examined ROR $\gamma \mathrm{t}$ translocation in treated cells. CX-4945 reduced the amount of nuclear ROR- $\gamma \mathrm{t}$ in a dose-dependent manner, but it did not affect the amount of ROR $\gamma \mathrm{t}$ in the cytosol, suggesting that CK2 inhibition suppressed the nuclear translocation of ROR- $\gamma \mathrm{t}$ (Figure $7 \mathrm{~d}$ ). These data indicate that CK2 regulates Th17 and Treg cell differentiation via the Akt/mTOR signaling pathway.

\section{DISCUSSION}

Here, we showed that CK2 (induced by TCR and co-stimulatory signals) controls the differentiation of CD4 $\mathrm{T}$ cells. The inhibition of $\mathrm{CK} 2$ using a selective inhibitor (CX-4945) blocked both STAT3 phosphorylation and the activation of the mTOR signaling pathway, resulting in the blockade of Th17 cell differentiation and a reciprocal increase in Treg cell differentiation.

TCR and CD28 signaling activates naive CD4 T cells through several signaling pathways. Although cytokines have a major role in CD4 $\mathrm{T}$ cell differentiation, it is also regulated by both the quantity and quality of the TCR and CD28 signals. ${ }^{17,32-34}$ For example, sustained TCR stimulation activates the PI3K/Akt/mTOR signaling pathway, which promotes the differentiation of inflammatory $\mathrm{T}$ cells and inhibits the de novo expression of Foxp3 and Treg cell differentiation. ${ }^{17}$ Here, we propose that CK2 is a mediator that forms a link between TCR/CD28 stimulation and PI3K/Akt/mTOR activation, and that CK2 is an important regulator of TCR-dependent CD4 $\mathrm{T}$ cell differentiation. Our study shows that the differentiation of naive CD4 T cells is influenced by TCR and CD28 signals in the absence of additional role of cytokines. 
a

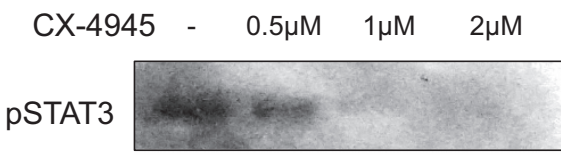

STAT3

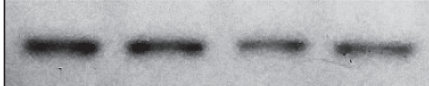

$\beta$-actin

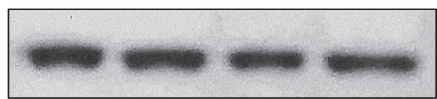

IL17A+ cells $(\%)$

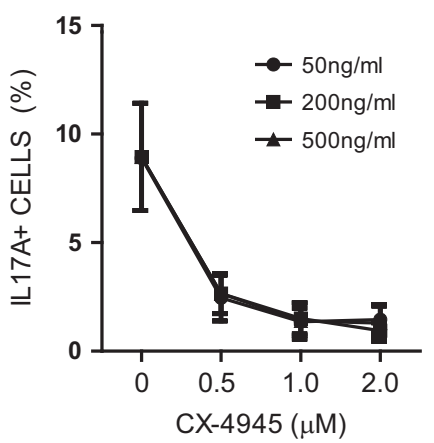

e

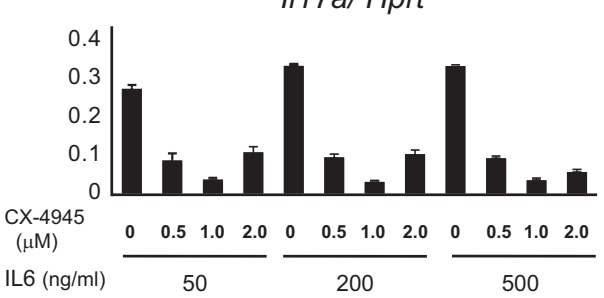

b

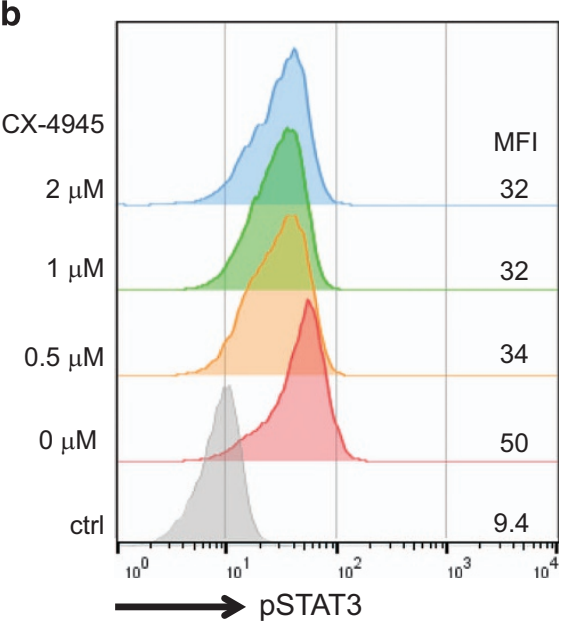

d Foxp3+ cells (\%)

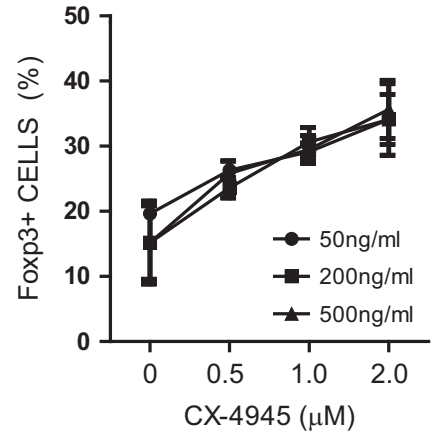

f

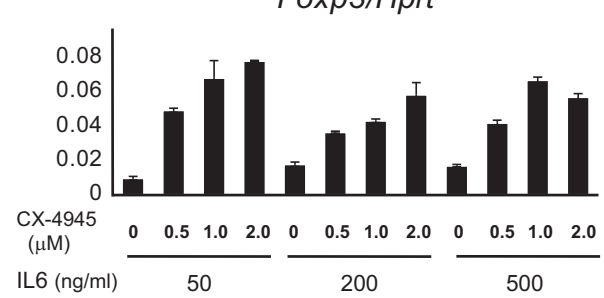

Figure 6 CX-4945 inhibits STAT3 phosphorylation downstream of IL-6 receptor signaling. (a) Immunoblot analysis of phosphorylated STAT3 and the total STAT3 in T cell lysates. Naive CD4 T cells were stimulated for $72 \mathrm{~h}$ under Th17-polarizing conditions in the presence of the indicated concentrations of CX-4945. (b) Flow cytometry analysis of phosphorylated STAT3. Naive CD4 T cells were stimulated for $48 \mathrm{~h}$ with $\alpha \mathrm{CD} 3$ and $\alpha \mathrm{CD} 28$ and then re-stimulated with IL- 6 for $15 \mathrm{~min}$. (c, d) Naive CD4 T cells were stimulated for 3 days with TGF $\beta$ and various concentrations of IL-6. CX-4945 was then added at the indicated doses, and the percentages of IL17A+ (c) and Foxp3+ (d) cells were measured by flow cytometry. (e, f) The relative mRNA expression of $/ 117 a$ and Foxp3 mRNA in cells prepared as in c, d. The error bars represent the s.d. The experiments were performed three times independently and yielded similar results.

Most studies on CK2 have focused on its overexpression and anti-apoptotic function in tumor cells. ${ }^{35}$ Thus, it is considered a potential therapeutic target. Indeed, some CK2 inhibitors are being assessed in ongoing pre-clinical trials. ${ }^{36}$ CX-4945 is one such inhibitor undergoing phase 1 clinical trials as a treatment for multiple myeloma (ClinicalTrials.gov NCT01199718) and phase 1/phase 2 trials as a treatment for cholangiocarcinoma (ClinicalTrials.gov NCT02128282). Recently, CD4 T cells have emerged as a great tool for cancer immunotherapy. The adoptive transfer of tumor antigen-specific $\mathrm{T}$ cells prevented tumor progression in a patient with metastatic cholangiocarcinoma. ${ }^{37}$ Th17 cells exhibit both pro- and antitumor functions, depending on the context. ${ }^{38} \mathrm{~A}$ drawback of CX-4945 is that it may induce tumor cell tolerance by regulating the development of $\mathrm{T}$ effector cells and Treg cells; therefore, the effects of the drug on antitumor immune responses need to be examined to prevent latent obstacles that may become apparent in upcoming clinical trials.

In humans, Th17 cells and their associated cytokines have a key role in many autoimmune diseases, including multiple sclerosis (MS), rheumatoid arthritis, psoriasis and inflammatory bowel disease. ${ }^{1}$ In most of these conditions, a reduced 


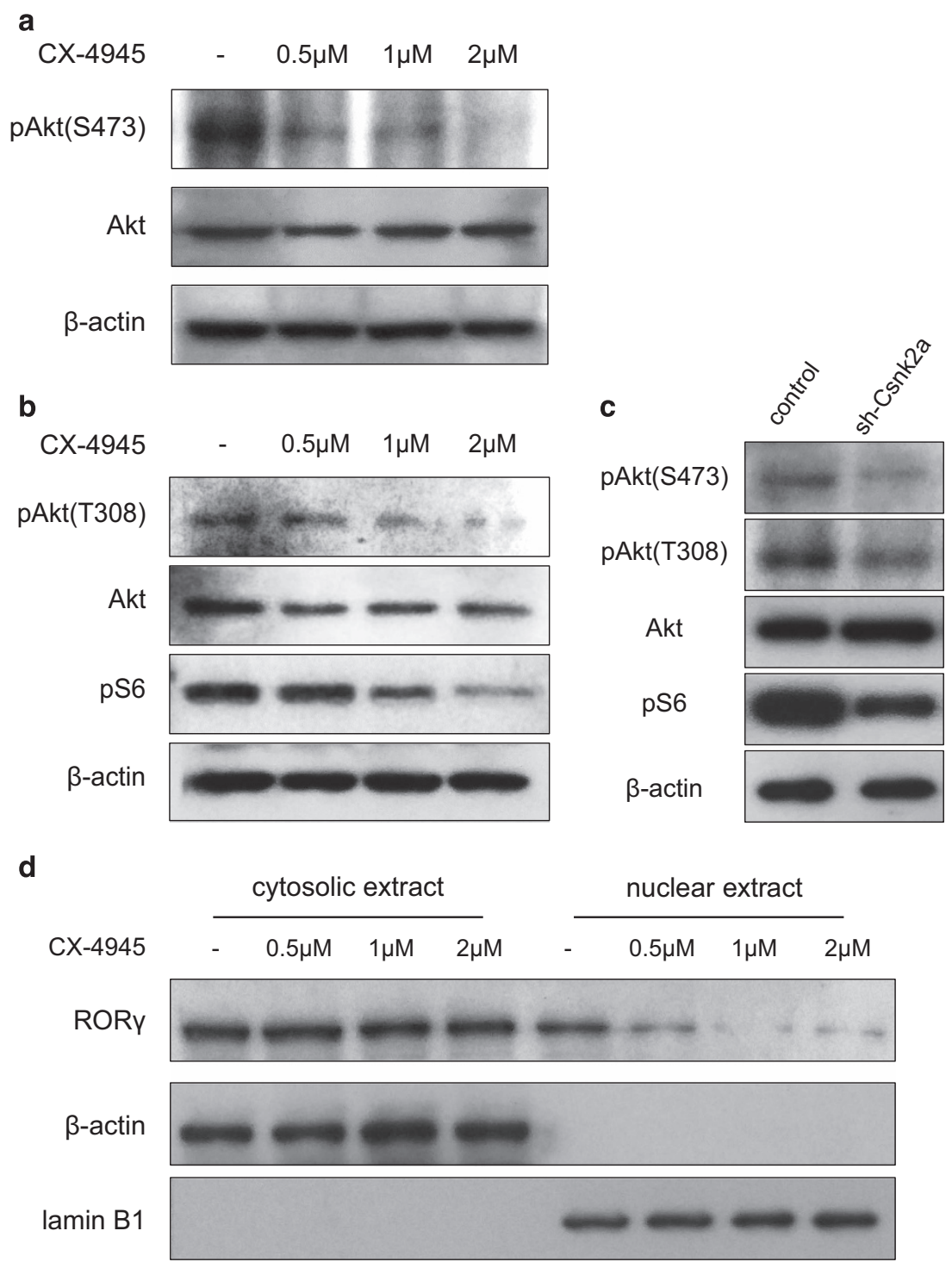

Figure 7 CX-4945 suppresses mTORC1 and mTOC2 signaling. (a) Immunoblot analysis of Akt phosphorylated on S473 and the total Akt in the whole-cell lysates. Naive CD4 T cells were stimulated under Th17-polarizing conditions in the presence of the indicated concentrations of CX-4945 and then re-stimulated. (b) Immunoblot analysis of Akt phosphorylated on S308, the total Akt and phosphorylated S6 in the whole-cell lysates prepared from Th17-differentiated cells. CX-4945 was then added at the indicated doses. (c) Naive CD4 T cells were stimulated and transduced with a retroviral vector containing a control vector or sh-Csnk2a. The cells were then stimulated for 3 days under Th17 differentiation conditions. The GFP+ cells were sorted and subjected to immunoblot analysis similar to $\mathbf{a}$, b. (d) The immunoblot analysis of ROR- $\gamma$ t. Naive CD4 T cells were stimulated under Th17-polarizing conditions in the presence of the indicated concentrations of CX-4945 and then re-stimulated. The cytosolic and nuclear extracts were then prepared. $\beta$-actin and lamin B1 were used as markers for the cytosolic and nuclear extracts, respectively. The experiments were performed three times independently and yielded similar results.

number/loss of function of Treg cells has been observed. ${ }^{39}$ MS is an inflammatory demyelinating disease of the CNS, which is induced by the activation of auto-reactive inflammatory $\mathrm{T}$ cells that then migrate to the CNS through the blood brain barrier (BBB). Many therapeutic strategies for MS target Th17-mediated pathways, including IFN- $\beta$ (FDA approved), which inhibits Th17 differentiation and induces Treg differentiation, and secukinumab (in clinical trials), a human antiIL-17A antibody that directly blocks IL-17A; both of these were first tested in EAE mice, an animal model of human MS. ${ }^{40-42}$
Here, we used CX-4945 to treat EAE mice and found that it led to a marked reduction in symptom severity. CX-4945 reduced the population of CD4 T cells in the CNS. Oral treatment with CX-4945 reduced the development of auto-reactive CD4 T cells and their migration to the periphery. CX-4945 can cross the $\mathrm{BBB},{ }^{43}$ so it can regulate these cells within the CNS. When differentiating CD4 T cells were exposed to CX-4945 for 36-72 $\mathrm{h}$ in vitro, the cell fates were still altered with the same tendency (data not shown). Therefore, it is likely that CX-4945 controls both the infiltration of peripheral effector $\mathrm{T}$ cells and 
the Th17/Treg balance in the CNS, even when administered after disease onset.

In conclusion, this study shows that CK2 has an essential role in promoting Th17 cell differentiation during TCR stimulation and IL-6 signaling, thereby regulating the Th17/Treg cell balance. Inhibiting CK2 with a small molecule inhibitor, CX-4945, had a positive therapeutic effect on autoimmune-mediated inflammation in vivo. Thus, we have identified both a novel mechanism underlying CD4 T cell differentiation and a potential new strategy for treating autoimmune diseases, including MS.

\section{CONFLICT OF INTEREST}

The authors declare no conflict of interest.

\section{ACKNOWLEDGEMENTS}

This work was supported by the National Research Foundation of Korea (NRF) grants funded by the Korean government (NRF-2014R1A2A1A11052545 and NRF-2015M3C9A2054020, NRF-2017R1A2B3008621 to GRL and 2014H1A8A1022457 to SWJ).

1 Tesmer LA, Lundy SK, Sarkar S, Fox DA. Th17 cells in human disease. Immunol Rev 2008; 223: 87-113.

2 Tabarkiewicz J, Pogoda K, Karczmarczyk A, Pozarowski P, Giannopoulos K. The role of IL-17 and Th17 lymphocytes in autoimmune diseases. Arch Immunol Ther Exp 2015; 63: 435-449.

3 Pelletier M, Girard D. Biological functions of interleukin-21 and its role in inflammation. Sci World J 2007; 7: 1715-1735.

4 Pan HF, Li XP, Zheng SG, Ye DQ. Emerging role of interleukin-22 in autoimmune diseases. Cytokine Growth Factor Rev 2013; 24: 51-57.

5 Sakaguchi S. Naturally arising CD4+ regulatory t cells for immunologic self-tolerance and negative control of immune responses. Annu Rev Immunol 2004; 22: 531-562.

6 Brunkow ME, Jeffery EW, Hjerrild KA, Paeper B, Clark LB, Yasayko SA et al. Disruption of a new forkhead/winged-helix protein, scurfin, results in the fatal lymphoproliferative disorder of the scurfy mouse. Nat Genet 2001; 27: $68-73$

7 Littman DR, Rudensky AY. Th17 and regulatory T cells in mediating and restraining inflammation. Cell 2010; 140: 845-858.

8 Yang XO, Nurieva R, Martinez GJ, Kang HS, Chung Y, Pappu BP et al. Molecular antagonism and plasticity of regulatory and inflammatory $T$ cell programs. Immunity 2008; 29: 44-56.

9 Dang EV, Barbi J, Yang HY, Jinasena D, Yu H, Zheng Y et al. Control of T(H) 17/T(reg) balance by hypoxia-inducible factor 1 . Cell 2011; 146: 772-784.

10 Cho ML, Kang JW, Moon YM, Nam HJ, Jhun JY, Heo SB et al. STAT3 and NF-kappaB signal pathway is required for IL-23-mediated IL-17 production in spontaneous arthritis animal model IL-1 receptor antagonist-deficient mice. J Immunol 2006; 176: 5652-5661.

11 Veldhoen M, Hocking RJ, Atkins CJ, Locksley RM, Stockinger B. TGFbeta in the context of an inflammatory cytokine milieu supports de novo differentiation of IL-17-producing T cells. Immunity 2006; 24: 179-189.

12 Ivanov II, McKenzie BS, Zhou L, Tadokoro CE, Lepelley A, Lafaille JJ et al. The orphan nuclear receptor RORgammat directs the differentiation program of proinflammatory IL-17+ T helper cells. Cell 2006; 126: $1121-1133$.

13 Yang XO, Panopoulos AD, Nurieva R, Chang SH, Wang D, Watowich SS et al. STAT3 regulates cytokine-mediated generation of inflammatory helper T cells. J Biol Chem 2007; 282: 9358-9363.

14 Dong C. Genetic controls of Th17 cell differentiation and plasticity. Exp Mol Med 2011; 43: 1-6.

$15 \mathrm{Chi} \mathrm{H}$. Regulation and function of mTOR signalling in T cell fate decisions. Nat Rev Immunol 2012; 12: 325-338.

16 Kurebayashi Y, Nagai S, Ikejiri A, Ohtani M, Ichiyama K, Baba Y et al. PI3K-Akt-mTORC1-S6K1/2 axis controls Th17 differentiation by regulating
Gfi1 expression and nuclear translocation of RORgamma. Cell Rep 2012; 1: 360-373.

17 Sauer S, Bruno L, Hertweck A, Finlay D, Leleu M, Spivakov M et al. T cell receptor signaling controls Foxp3 expression via PI3K, Akt, and mTOR. Proc Natl Acad Sci USA 2008; 105: 7797-7802.

18 Delgoffe GM, Kole TP, Zheng Y, Zarek PE, Matthews KL, Xiao B et al. The mTOR kinase differentially regulates effector and regulatory $T$ cell lineage commitment. Immunity 2009; 30: 832-844.

19 Pinna LA, Meggio F. Protein kinase CK2 ('casein kinase-2') and its implication in cell division and proliferation. Prog Cell Cycle Res 1997; 3: 77-97.

20 Dominguez I, Sonenshein GE, Seldin DC. Protein kinase CK2 in health and disease: CK2 and its role in Wnt and NF-kappaB signaling: linking development and cancer. Cell Mol Life Sci 2009; 66: 1850-1857.

21 Zheng Y, Qin H, Frank SJ, Deng L, Litchfield DW, Tefferi A et al. A CK2-dependent mechanism for activation of the JAK-STAT signaling pathway. Blood 2011; 118: 156-166.

22 Piazza FA, Ruzzene M, Gurrieri C, Montini B, Bonanni L, Chioetto G et al. Multiple myeloma cell survival relies on high activity of protein kinase CK2. Blood 2006; 108: 1698-1707.

23 Silva A, Yunes JA, Cardoso BA, Martins LR, Jotta PY, Abecasis M et al. PTEN posttranslational inactivation and hyperactivation of the PI3K/Akt pathway sustain primary T cell leukemia viability. J Clin Invest 2008; 118: 3762-3774

24 Ulges A, Klein M, Reuter S, Gerlitzki B, Hoffmann M, Grebe N et al. Protein kinase $\mathrm{CK} 2$ enables regulatory T cells to suppress excessive $\mathrm{TH} 2$ responses in vivo. Nat Immunol 2015; 16: 267-275.

25 Hwang SS, Jang SW, Kim MK, Kim LK, Kim BS, Kim HS et al. YY1 inhibits differentiation and function of regulatory $\mathrm{T}$ cells by blocking Foxp3 expression and activity. Nat Commun 2016; 7: 10789.

26 Siddiqui-Jain A, Drygin D, Streiner N, Chua P, Pierre F, O'Brien SE et al. CX-4945, an orally bioavailable selective inhibitor of protein kinase CK2, inhibits prosurvival and angiogenic signaling and exhibits antitumor efficacy. Cancer Res 2010; 70: 10288-10298.

27 Chon HJ, Bae KJ, Lee Y, Kim J. The casein kinase 2 inhibitor, CX-4945, as an anti-cancer drug in treatment of human hematological malignancies. Front Pharmacol 2015; 6: 70.

28 Lee K, Gudapati P, Dragovic S, Spencer C, Joyce S, Killeen N et al. Mammalian target of rapamycin protein complex 2 regulates differentiation of Th1 and Th2 cell subsets via distinct signaling pathways. Immunity 2010; 32: 743-753.

29 Coyle AJ, Lehar S, Lloyd C, Tian J, Delaney T, Manning S et al. The CD28-related molecule ICOS is required for effective T cell-dependent immune responses. Immunity 2000; 13: 95-105.

30 Di Maira G, Salvi M, Arrigoni G, Marin O, Sarno S, Brustolon F et al. Protein kinase CK2 phosphorylates and upregulates Akt/PKB. Cell Death Differ 2005; 12: 668-677.

31 Miller SJ, Lou DY, Seldin DC, Lane WS, Neel BG. Direct identification of PTEN phosphorylation sites. FEBS Lett 2002; 528: 145-53.

32 Tubo NJ, Jenkins MK. TCR signal quantity and quality in CD4+ T cell differentiation. Trends Immunol 2014; 35: 591-596.

33 Tao X, Constant S, Jorritsma P, Bottomly K. Strength of TCR signal determines the costimulatory requirements for Th1 and Th2 CD4+ T cell differentiation. J Immunol 1997; 159: 5956-5963.

34 Gomez-Rodriguez J, Wohlfert EA, Handon R, Meylan F, Wu JZ, Anderson SM et al. Itk-mediated integration of $\mathrm{T}$ cell receptor and cytokine signaling regulates the balance between Th17 and regulatory T cells. J Exp Med 2014; 211: 529-543.

35 Hanif IM, Shazib MA, Ahmad KA, Pervaiz S. Casein kinase II: an attractive target for anti-cancer drug design. Int J Biochem Cell Biol 2010; 42 1602-1605.

36 Duncan JS, Litchfield DW. Too much of a good thing: the role of protein kinase CK2 in tumorigenesis and prospects for therapeutic inhibition of CK2. Biochim Biophys Acta 2008; 1784: 33-47.

37 Tran E, Turcotte S, Gros A, Robbins PF, Lu YC, Dudley ME et al. Cancer immunotherapy based on mutation-specific CD4+ $T$ cells in a patient with epithelial cancer. Science 2014; 344: 641-645.

38 Guery L, Hugues S. Th17 cell plasticity and functions in cancer immunity. Biomed Res Int 2015; 2015: 314620.

39 Lad DP, Varma S, Varma N, Sachdeva MU, Bose P, Malhotra P. Regulatory T-cell and T-helper 17 balance in chronic lymphocytic leukemia progression and autoimmune cytopenias. Leuk Lymphoma 2015; 56 : 2424-2428. 
40 Sweeney CM, Lonergan R, Basdeo SA, Kinsella K, Dungan LS, Higgins SC et al. IL-27 mediates the response to IFN-beta therapy in multiple sclerosis patients by inhibiting Th17 cells. Brain Behav Immun 2011; 25: 1170-1181.

41 Hofstetter HH, Ibrahim SM, Koczan D, Kruse N, Weishaupt A, Toyka KV et al. Therapeutic efficacy of IL-17 neutralization in murine experimental autoimmune encephalomyelitis. Cell Immunol 2005; 237: 123-130.

42 Dos Passos GR, Sato DK, Becker J, Fujihara K. Th17 cells pathways in multiple sclerosis and neuromyelitis optica spectrum disorders: pathophysiological and therapeutic implications. Mediators Inflamm 2016; 2016: 5314541.

43 Kim H, Lee KS, Kim AK, Choi M, Choi K, Kang M et al. A chemical with proven clinical safety rescues Down-syndrome-related phenotypes in through DYRK1A inhibition. Dis Model Mech 2016; 9: 839-848. (c) (1) () $€$ This work is licensed under a Creative Commons Attribution-NonCommercial-NoDerivs 4.0 International License. The images or other third party material in this article are included in the article's Creative Commons license, unless indicated otherwise in the credit line; if the material is not included under the Creative Commons license, users will need to obtain permission from the license holder to reproduce the material. To view a copy of this license, visit http://creativecommons.org/licenses/by-nc-nd/4.0/

(C) The Author(s) 2017

Supplementary Information accompanies the paper on Experimental \& Molecular Medicine website (http://www.nature.com/emm) 